\title{
Vertical Farming as a Game Changer for BECCS Technology Deployment
}

\author{
Zoe M. Harris $1, *(1)$ and Yiannis Kountouris ${ }^{2}$ (D) \\ 1 Centre for Environment and Sustainability, University of Surrey, Guildford GU2 7XH, UK \\ 2 Centre for Environmental Policy, Imperial College London, London SW7 1NA, UK; \\ i.kountouris@imperial.ac.uk \\ * Correspondence: z.harris@surrey.ac.uk; Tel.: +44-(0)-1483-686683-4
}

Received: 3 September 2020; Accepted: 28 September 2020; Published: 5 October 2020 updates

\begin{abstract}
The Intergovernmental Panel on Climate Change (IPCC) report that to limit warming to $1.5^{\circ} \mathrm{C}$, Bioenergy with Carbon Capture and Storage (BECCS) is required. Integrated assessment models (IAMS) predict that a land area between the size of Argentina and Australia is required for bioenergy crops, a 3-7 time increase in the current bioenergy planting area globally. The authors pose the question of whether vertical farming (VF) technology can enable BECCS deployment, either via land sparing or supply. VF involves indoor controlled environment cultivation, and can increase productivity per unit land area by $5-10$ times. VF is predominantly being used to grow small, high value leafy greens with rapid growth cycles. Capital expenditure, operational expenditure, and sustainability are challenges in current VF industries, and will affect the ability to utilise this technology for other crops. The authors argue that, whilst challenging, VF could help reach wider climate goals. Application of VF for bioenergy crops could be a game changer in delivering BECCS technologies and may reduce the land footprint required as well as the subsequent associated negative environmental impacts. VF bioenergy could allow us to cultivate the future demand for bioenergy for BECCS on the same, or less, land area than is currently used globally.
\end{abstract}

Keywords: vertical farming; bioenergy; BECCS; land use change; indoor agriculture; land sparing; food

\section{Introduction}

In light of the recent Intergovernmental Panel on Climate Change (IPPC) $1.5{ }^{\circ} \mathrm{C}$ report [1], we are facing some sobering facts about our changing planet and the scale of action required to limit future devastating impacts. Globally, we face a compendium of problems affecting our ability to provide ecosystem services for current and future populations. Anthropogenic greenhouse gas (GHG) emissions continue to rise due to fossil fuel usage and land use change (LUC), exacerbating climate change. Global mean surface temperature has increased by c. $1^{\circ} \mathrm{C}$ since pre-industrial levels, with integrated assessment models (IAMs) predicting to reach a $1.5^{\circ} \mathrm{C}$ rise between 2030 and 2052 [1] unless we intervene.

To meet our climate targets of limiting global temperature rise to between $1.5-2{ }^{\circ} \mathrm{C}$, we need to reduce GHGs, eventually reaching negative emissions. A global effort has been instigated to limit warming by $1.5^{\circ} \mathrm{C}$ [2]. To do so, carbon dioxide $\left(\mathrm{CO}_{2}\right)$ emissions must decline by $45 \%$ from 2010 levels by 2030, and have reached net zero by 2050 [1]. All scenarios which limit warming require the use of negative emissions technologies (NETs), the most prominent being Bioenergy with Carbon Capture and Storage (BECCS) [3].

For BECCS deployment to have a meaningful effect on GHG reduction, vast amounts of land will be needed to cultivate bioenergy crops, which is itself expected to have substantial environmental 
impacts. To achieve the $1.5^{\circ} \mathrm{C}$ target, the land required for bioenergy crops is predicted to reach 2.8 million $\mathrm{km}^{2}$ (283 Mha) by 2050 [1], or a land area the size of Argentina (Figure 1). In scenarios with high overshoot (a continued GHG intensive life style and high reliance on BECCS), 7.2 million $\mathrm{km}^{2}$ (724 Mha) [1], or a land area the size of Australia, is required. Current global bioenergy land use is estimated at 98 Mha [4], therefore three to seven times the amount of current land used would need to be converted to meet 2050 levels. Land use change on that scale is expected to result in a number of detrimental impacts [1], including release of GHG emissions, increased pressure on water resources, impacts on biodiversity, and climate feedbacks, to name a few.

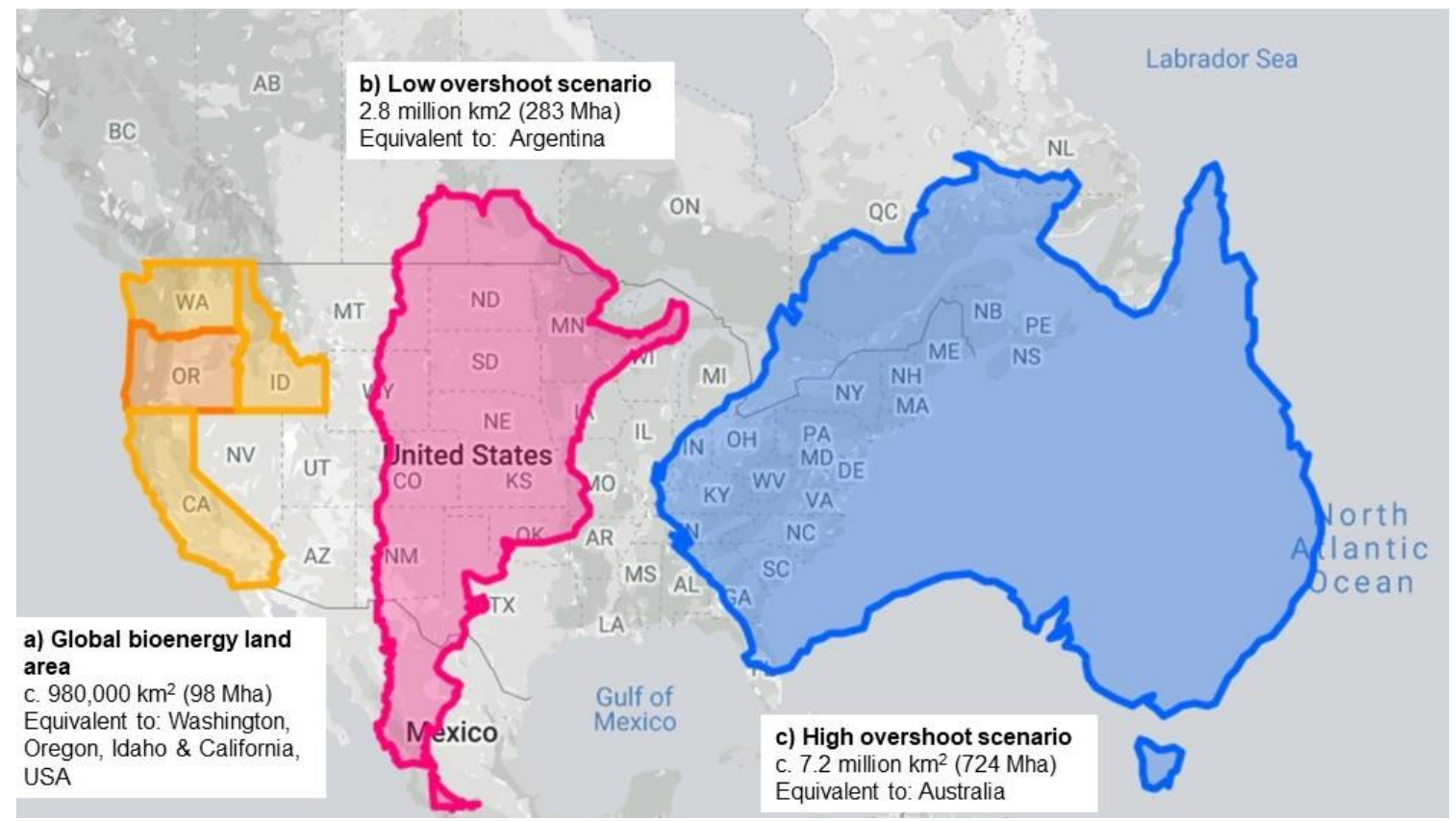

Figure 1. Relative size land area required for bioenergy production, as part of Bioenergy with Carbon Capture and Storage (BECCS), under IPCC 1.5 scenarios by 2050. (a) current global bioenergy land area, (b) IPCC 'low overshoot' scenario for bioenergy production for BECCS, (c) IPCC 'high overshoot' scenario for bioenergy production for BECCS. Country sizes overlaid the USA for size comparator.

Vertical farming (VF), stacked indoor controlled environment crop cultivation, is able to support BECCS deployment in two keys ways, through land sparing or through bioenergy supply (Figure 2). Land sparing is the concept in which crops, which are currently commercially successful in vertical farming, are removed from field production to free up "spare land". This land could then be cultivated for bioenergy production, therefore contributing to wider climate and energy goals. The other option is by bioenergy supply, whereby growing bioenergy in vertical farms supplements the existing supply streams from traditional field grown operations, occupying a smaller land footprint. Whilst the long-term feasibility and sustainability of the land sparing options has not been fully quantified, this route would be possible given commercial and political will as there would not be significant technological barriers to overcome. However, vertical farming bioenergy has the potential to be an innovative and disruptive technology, despite current barriers.

The purpose of this article is to understand the current opportunities and challenges of VF, introduce vertical farming bioenergy (VFB), acknowledge current limitations, propose mitigating actions which might make this technology more feasible in the future, and pose a number of open questions. Vertical farming, if done right, could have the potential to supply more than just small, high value leafy greens, and support wider climate goals. 
a) Land Sparing
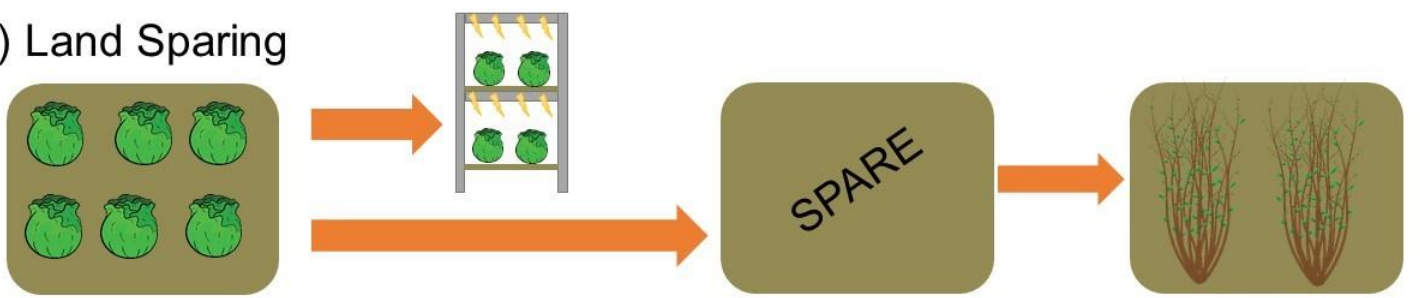

b) Bioenergy Supply
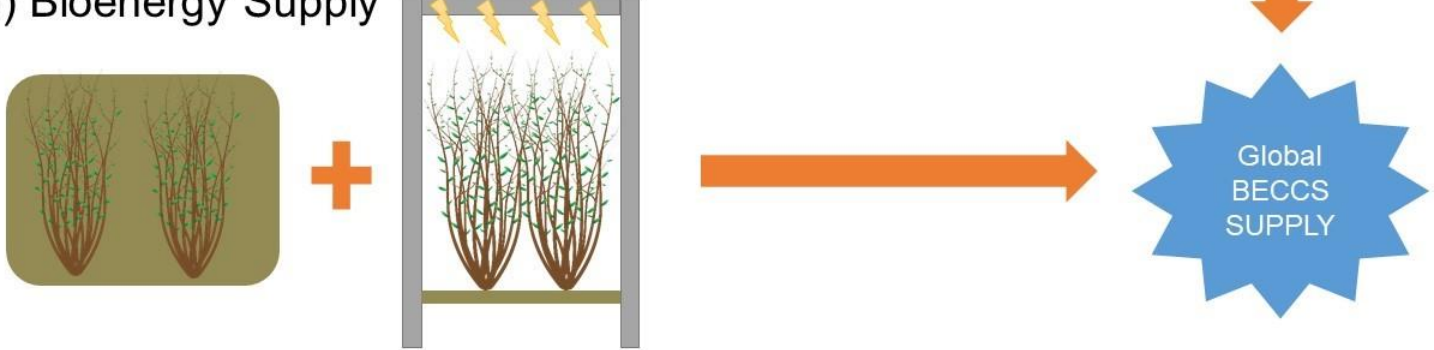

Figure 2. Options for how vertical farming could enable BECCS deployment. (a) Land Sparing-freeing up land to grow bioenergy crops by moving leafy greens into vertical farming, where they are currently commercially viable. (b) Bioenergy Supply_vertical farming bioenergy (VFB) as an addition to field grown bioenergy to contribute to global BECCS supply.

\section{Status Quo: Vertical Farming}

Vertical farming takes advantage of the vertical plane to cultivate crops in stacks in a controlled environment where optimal conditions for growth are maintained, allowing greater control over cultivation and ultimately more biomass production per unit area compared to traditional farming methods [5]. At present, VF is mainly used to grow small, high value, leafy green crops, which have a short time from planting to harvesting. Within these systems, a constant temperature and humidity is maintained and plants are typically grown using hydroponic or aeroponic techniques in a closed-loop recycled system, supplied with LED lighting and $\mathrm{CO}_{2}$ fertilisation. This approach optimises plant growth and results in reduced water and nutrient inputs. For example, lettuce grown in VF is ready for harvest in 28 days, compared to 80 days in the field [6], with zero pesticides and up to $50 \%$ less fertilizer [7]. Vertical farming also allows crops to be cultivated in harsh environments, or where extreme weather events would make outdoor cultivation challenging or impossible. Some argue that vertical farming can help address food poverty and food islands in urban centres due to ease of access to fresh produce [8]. The potential benefits and drawbacks of using VF for plant cultivation can be seen in Table 1 [7].

Reducing the growing period and optimising growing conditions increase production cost relative to traditional technologies. Capital expenditure (CAPEX) for VF is higher than traditional glasshouse or outdoor cultivation. Energy is required for artificial lighting, water distribution systems, heating and cooling, as well as the sensors and control units to monitor and adjust these parameters. Therefore, there is a high operation expenditure (OPEX) associated with high electricity usage, as well as labour costs. In a survey of over 150 indoor agriculture operations, only half were operating at a profit, with an average age of 7 years in operation [9]. Increased production cost relative to traditional methods imply profitable crops are typically physically short, with a brief growth cycle, highly perishable, high revenue crops targeted to speciality markets [9]. The lifespan of a typical operation has not been well studied; however, once constructed, the infrastructure is expected to last some decades [7]. As with all industries which utilize technology, there will be requirements to update existing infrastructure (such as LED lights) to maintain efficiency, and therefore enterprises must accept economic depreciation from technological advancement [7]. In addition to financial viability, there are questions over VF's environmental sustainability. Vertical farming can reduce the land, water, and nutrient footprint of 
crops; however, the emissions associated with the building infrastructure and an around-the-clock energy supply could be significant.

Table 1. Potential benefits and drawbacks of using vertical farming for plant cultivation.

\begin{tabular}{|c|c|}
\hline Benefits & Drawbacks \\
\hline $\begin{array}{l}\text { Reduced land footprint-Productivity per unit } \\
\text { land area is higher than traditional agriculture } \\
\text { due to use of vertical plane of cultivation. }\end{array}$ & $\begin{array}{l}\text { CAPEX-Capital expenditure, or start-up costs, are very } \\
\text { high to create a controlled environment and implement } \\
\text { growing infrastructure. }\end{array}$ \\
\hline $\begin{array}{l}\text { Shorter time to harvest-Increased rate of crop } \\
\text { growth due to optimised conditions therefore } \\
\text { ready for harvest sooner. }\end{array}$ & $\begin{array}{l}\text { OPEX-Operational expenditure is also high compared } \\
\text { to traditional farming operations. Predominantly due to } \\
\text { labour costs for skilled workers, rent, and energy costs to } \\
\text { maintain a controlled environment and grow crops. }\end{array}$ \\
\hline $\begin{array}{l}\text { Reduced inputs-Closed-loop system, therefore } \\
\text { water and nutrients are recycled, and there is no } \\
\text { loss to the environment as is often seen in } \\
\text { traditional farming. }\end{array}$ & $\begin{array}{c}\text { Energy usage-Heating, cooling, and air-conditioning } \\
\text { (HVAC) to maintain a controlled environment are } \\
\text { constantly required. HVAC, as well as } 16-18 \text { h of LED } \\
\text { lighting for growing crops demand a high } \\
\text { electricity investment. }\end{array}$ \\
\hline $\begin{array}{l}\text { Cultivation in harsh environments-Closed } \\
\text { system and supply of all conditions required for } \\
\text { growth allows cultivation in harsh environments } \\
\text { such as deserts, artic zones, or where extreme } \\
\text { weather events are prevalent. }\end{array}$ & $\begin{array}{l}\text { Crop suitability-Current technological constraints and } \\
\text { cost limitations mean only certain crops are suitable for } \\
\text { growth. Most crops are amenable to cultivation in } \\
\text { hydroponics and under artificial lights; however, these } \\
\text { have not all been optimised or commercialised. }\end{array}$ \\
\hline $\begin{array}{l}\text { Food equality-Cultivation in urban and } \\
\text { sub-urban environmental allows access to fresh } \\
\text { produce where this may be commonly lacking, } \\
\text { such as food deserts in impoverished cities. }\end{array}$ & $\begin{array}{l}\text { Crop retail price-Due to high CAPEX and OPEX, crops } \\
\text { grown in VF demand a higher retail price. }\end{array}$ \\
\hline $\begin{array}{l}\text { Crop quality-Increased aromatics or antioxidant } \\
\text { strains can be produced in VF as conditions can be } \\
\text { manipulated, and stresses applied with precision. }\end{array}$ & $\begin{array}{c}\text { Food poverty-A high retail price of crops grown in VF } \\
\text { mean that these crops are only available in bespoke and } \\
\text { niche markets and do little to affect social equality and } \\
\text { food poverty in urban centres. }\end{array}$ \\
\hline \multicolumn{2}{|l|}{$\begin{array}{l}\text { Reduced losses and supply chain emissions-If } \\
\text { cultivation takes place in urban/per-urban spaces, } \\
\text { distance to the end user is reduced, therefore } \\
\text { reducing supply chain losses incurred through } \\
\text { long distance transport. This also reduces supply } \\
\text { chain emissions associated with transport. }\end{array}$} \\
\hline \multicolumn{2}{|l|}{$\begin{array}{l}\text { Job creation-Labour required for vertical } \\
\text { farming }(\mathrm{VF}) \text { is higher than traditional agriculture, } \\
\text { and a more specialised role attracts a higher salary } \\
\text { than traditional farm labour. }\end{array}$} \\
\hline $\begin{array}{l}\text { Automation-Whilst this threatens job creation } \\
\text { benefits, it is able to reduce running costs as } \\
\text { automating seeding results in increased yields } \\
\text { (reduced human error) and a reduction in labour } \\
\text { costs (typically make up third to half of } \\
\text { operational expenditure). }\end{array}$ & \\
\hline
\end{tabular}

At present there is little to no policy support for new agri-tech of this type, despite high investments in the private sector. In 2017, global annual investment in agriculture was c. $\$ 73$ billion dollars [10]; in the same year, $\$ 1.5$ billion was invested in agri-tech [11], the highest investment to date. Industry leaders Plenty received a $\$ 200$ million investment from Japanese tech investor SoftBank Vision to expand operations into Asia, with over 300 indoor farms planned [12]. This investment demonstrates that these systems are considered to be commercially viable for certain types of crops, within certain markets. 


\section{New Concept: Vertical Farming Bioenergy}

If the advantages that have been observed in lettuce VF production could be realised for bioenergy crops, then we would be able to reduce the growing period, inputs, and waste from the system and obtain far more biomass per unit area compared to traditional farming. Given the productivity increase in leafy greens has been 5-10 times on the same land area [7], and 3-7 times the amount of land is required for conventional BECCS—utilising VFB could allow us to meet the future BECCS demand on the same or less land that is currently being used for bioenergy globally.

For VFB to present itself as a viable method to produce bioenergy, a leap must be made from small scale, specialised production to large, industrial scale production. This will necessitate significant infrastructure investment. To offset the challenges raised by large start-up costs, design choices can be made to minimise cost and environmental impact. Mixes of renewables could be used to power VFB, solar arrays or wind turbines would offer a cleaner energy mix compared to many current national grids, albeit at a potentially more costly price. A circular-economy approach could be applied, utilising waste from the farm for anaerobic digestion or using a proportion of the biomass to route back into powering the farm. VFB installations could, where possible, be located in proximity to power plants to reduce transportation costs and emissions. This would be attractive where current alternatives involve long-distance transport of biomass feedstocks. Siting of VFB on degraded land, or land unsuitable for cultivation or habitation would avoid competition with other land uses, and could minimise potential negative impacts incurred from LUC. Advances in automation could allow this system to have zero human interference—crops could be seeded, cultivated, harvested, and transported to the power generation site just next door. Use of computer monitoring and an advanced network of sensors could limit labour costs; a lettuce operation in Japan has shown that automation can reduce OPEX by up to $40 \%$ [7] due to the benefits described in Table 1. Significant research and commercial efforts are focused on automation and advancement of LED lighting, as this, and VF technology advance, it is likely that the technology will become cheaper over time, therefore making VFB more realistic in the future.

Despite this potential, there are a number of challenges in getting VF to work for bioenergy, including both physical and economic constraints (Table 2).

Table 2. Key challenges of vertical farming bioenergy, compared to crops currently grown in vertical farms.

\begin{tabular}{c}
\hline \multicolumn{1}{c}{ Physical Constraints } \\
\hline Size \\
$\begin{array}{l}\text { First-generation (1G) bioenergy crops, such as maize and soybean, can grow as tall as } \\
\text { 0.5-3 m; and second-generation (2G) bioenergy crops, such as short rotation coppice willow } \\
\text { and Miscanthus, reach 3-5 m tall outdoors. These are clearly much larger than the likes of } \\
\text { lettuce, tomatoes, and flowers which are currently being grown in VF systems. Infrastructure } \\
\text { developments are needed to allow for these larger crops. This will reduce biomass per unit } \\
\text { area, due to increased vertical space occupation, compared to leafy greens. }\end{array}$ \\
$\begin{array}{l}\text { The life cycle of } 1 \mathrm{G} \text { and } 2 \mathrm{G} \text { bioenergy crops are longer than that of lettuce. First generation } \\
\text { bioenergy crops are harvested on an annual cycle, and 2G crops between 1-4 years } \\
\text { depending on the specific crop. If they were able to see a reduction in life cycle as per lettuce, } \\
\text { this could be reduced to 0.5 years, though this is yet to be experimental evidence of this for } \\
\text { bioenergy crops. Therefore, there are questions around the amount of energy invested vs. } \\
\text { the amount of energy out. }\end{array}$ \\
$\begin{array}{l}\text { Life Cycle } \\
\text { Lettuce VF farms are profitable due to the high market price lettuce commands. In contrast, } \\
\text { market prices for dedicated bioenergy feedstocks are low due to the presence of many } \\
\text { suitable substitutes such as wood pellets made primarily from low value and "waste" wood. } \\
\text { The cost of bioenergy VF production must decrease substantially for it to become } \\
\text { economically viable under current market conditions. }\end{array}$ \\
\hline
\end{tabular}


Currently and considering the aforementioned limitations, there are significant hurdles for the implementation of VF. However, it could also be worth considering other crops which might be suitable in these systems such as staple food crops or medicinal plants, which are physically smaller with higher retail values, therefore more technically and economically viable.

In order to overcome these challenges, a number of mitigation strategies may make this technology more viable:

1. Future energy mix: Moving towards decarbonisation, the fuel mix of nations committed to meeting climate change targets will shift from fossil-based to renewables-based. There are currently 57 counties with $100 \%$ renewable electricity targets, such as Denmark with already over $50 \%$ of their electricity generation coming from renewables [13]. Therefore, the sustainability VFB will be improved if utilising a renewable energy system.

2. Breeding: The current stock of bioenergy crops have been bred for many years to withstand outdoor conditions with characteristics which are often the opposite of what is ideal for indoor cultivation. Breeding programs could be used to design these crops to be more suitable to growing indoors-short, thick, and energy dense crops which can grow at accelerated rates, in a short time frame. Given the time required for breeding programs, and the imminent pressure of global change, genetic modification would be a more suitable tool for rapid crop redesign. CRISPR-Cas9 genome editing has recently been used to develop compact, early yielding tomatoes for vertical farming [14].

3. Policy: Policy can influence VF use for bioenergy production and will likely be essential to the commercial success of VFB. Carbon pricing can increase the attractiveness of bioenergy feedstock and improve the financial viability of VFB.

Vertical farming bioenergy may offer a lower risk investment option in a transition towards a low carbon energy system and economy. As the frequency of crop-spoiling weather events increases, the investment risk in controlled environment agriculture decreases due to the guarantee of harvest. Should these weather events be extended to bioenergy crop failure in the future, it could be argued that investment in VF may provide a lower risk investment as the environmental impacts are known and constant in this system, with commodity price remaining the primary driver for investment. Transitioning to a low-carbon economy will require substantial investment, and there is added risk for investors in bioenergy who need to do so "at an affordable cost, and which meet appropriate sustainability criteria" [15]. Therefore, there are questions around if VFB would be able to produce feedstocks that would meet sustainability criteria due to the environmental footprint from maintaining a controlled environment. Conversely, undergoing LUC will have an impact that will remain largely unknown until the transition is complete, such as impacts on biodiversity and GHG emissions, the burdens of which investors will not bear. Though this can be predicated to some extent based on site characteristics, there is the added uncertainty of the impact of adverse weather events to climate change on such systems. Controlled environment agriculture will allow for reliable crop yields in harsh conditions, in spite of weather or climate change related effects.

\section{Land Sparing vs. Bioenergy Supply}

Cultivating bioenergy crops within VF does hold potential to produce bioenergy crops at the scale required to meet global climate goals, but immediate implementation is a challenge The more immediate route through which VF can support BECCS deployment is via land sparing, whereby commercially viable crops such as leafy greens are moved out of field production into VF production, thereby freeing "spare" land for bioenergy cultivation. This approach has the potential to support both food and energy security and could have a myriad of environmental benefits, for example, land use change from arable to second generation bioenergy reduces GHG emissions, increases soil carbon [16], and provides high value ecosystem services [17]. Further research is required to understand the 
extent to which VF, through land sparing, may support wider climate goals and what the associated environmental and socio-economic benefits and challenges may be.

\section{Outlook}

Adapting VF to bioenergy, and beyond leafy greens allows us to consider the possibility of cultivating a whole suite of economically and socially important crops. With a lack of political and financial incentives for bioenergy crop cultivation, and a paucity of sustainable technological infrastructure to cultivate such crops in vertical farming, VFB remains ambitious. However, asking the question about bioenergy crops allows us to consider a range of options for this technology and what may be possible. Products from VF, at present, are only for niche markets. The method of manufacturing attracts and requires a premium price, resulting in production of costly leafy greens sold in supermarkets and herbs/edible flowers for high-end restaurants. Leafy greens only make up a small proportion of diets; in 2015, the global average per capita consumption of lettuce was $2.88 \mathrm{~kg} /$ year [18], compared to wheat and rice at 67.1 and $53.6 \mathrm{~kg} /$ year respectively $[19,20]$. Therefore, we may consider application of this technology in the food sectors where it can cultivate more highly consumed crops, or through providing land sparing potential for these crops. Medicinal crops, such as marijuana, are predominantly commercially cultivated indoors with many growers expanding into VF systems [21], demonstrating that cultivation of crops larger than leafy greens is technologically and economically viable.

Whilst this paper has considered some of the benefits and challenges of VFB, there are more questions than answers at this stage. Some key questions which need to be addressed in further research are:

- How will VF technology develop over time, and how will costs be reduced? Could we see rapid price-drop progression as per solar technology?

- Will there be an increasing demand for BECCS, and will policy incentivise its deployment? Within this, will there be sufficient policy support to make VFB economical?

- Are staple food crops and medicinal plants a suitable middle ground for cultivation in these systems, and should this be where our efforts are focused?

- How can a whole systems, or circular-economy approach be applied to integrate VF and VFB into other systems, such as renewable energy technologies, waste management, or other food production systems?

- Can utilising this technology for food create "spare land", which can be put into bioenergy cultivation? What is the land potential and what are the wider environmental and socio-economic impacts of this approach?

If we can make VF bioenergy work, there is potential that it could play a game changing role in enabling mass rapid deployment of BECCS technologies. Sustainable VFB could help meet bioenergy targets quickly, and avoid detrimental impacts from extensive LUC. Further research is required to better understand the energy balance and sustainability of using VF for small food crops as we are now, and consider how we may be able to adapt these systems to the crops of the future.

Author Contributions: Conceptualization, Z.M.H.; writing—original draft preparation, Z.M.H.; writing一review and editing, Z.M.H., Y.K.; funding acquisition, Z.M.H. All authors have read and agreed to the published version of the manuscript.

Funding: Z.M.H. was funded by a NERC Industrial Innovation Fellowship, grant number NE/R013314/1.

Acknowledgments: With thanks to the PFDC and Mark Burgman for comments on early drafts. And to the reviewers for their helpful insights which have improved the MS.

Conflicts of Interest: The authors declare no conflict of interest. 


\section{References}

1. IPCC. IPCC Global Warming of $1.5^{\circ} \mathrm{C}$ an IPCC Special Report on the Impacts of Global Warming of $1.5^{\circ} \mathrm{C}$ above Pre-Industrial Levels and Related Global Greenhouse Gas Emission Pathways. In In The Context of Strengthening the Global Response to the Threat of Climate Change; World Meteorological Organization: Geneva, Switzerland, 2018; pp. 5-7.

2. United Nations. Adoption of the Paris Agreement; United Nations: San Francisco, CA, USA, 2015.

3. Smith, P.; Davis, S.J.; Creutzig, F.; Fuss, S.; Minx, J.; Gabrielle, B.; Kato, E.; Jackson, R.B.; Cowie, A.; Kriegler, E.; et al. Biophysical and economic limits to negative CO2 emissions. Nat. Clim. Chang. 2015, 6, 42-50. [CrossRef]

4. Strapasson, A.; Woods, J.; Chum, H.; Kalas, N.; Shah, N.; Rosillo-Calle, F. On the global limits of bioenergy and land use for climate change mitigation. GCB Bioenergy 2017, 9, 1721-1735. [CrossRef]

5. Despommier, D. Growing Skyscrapers: The Rise of Vertical Farms. Sci. Am. 2009, 301, 80-87. [CrossRef] [PubMed]

6. V-Farm V-Farm|Catalogue. Available online: http://www.v-farm.co.uk/vfarm-catalogue/ (accessed on 21 October 2018).

7. Kozai, T.; Nui, G.; Takagaki, M. (Eds.) Plant Factory: An Indoor Vertical Farming System for Efficient Quality Food Production; Elsevier: London, UK, 2015; ISBN 9780128017753.

8. Santo, R.; Palmer, A.; Kim, B. Vacant Lots to Vibrant Plots: A Review of the Benefits and Limitations of Urban Agriculture; John Hopkins Center for a Livable Future: Baltimore, MD, USA, 2016; p. 35.

9. Agrilyst. State of Indoor Farming; Artemis: Brooklyn, NY, USA, 2017.

10. Valoral Advisors. 2018 Global Food E Agriculture Investment Outlook Investing Profitably whilst Fostering a Better Agriculture; Valoral Advisors: Buenos Aires, Argentina, 2018.

11. Arama Kukutai. Spencer Maughan How the AgTech Investment Boom Will Create A Wave of Agriculture Unicorns. Forbes. Available online: https://www.forbes.com/sites/outofasia/2018/01/16/how-the-agtechinvestment-boom-will-create-a-wave-of-agriculture-unicorns/\#7321f67a562b (accessed on 30 July 2018).

12. Garfield, L. A Jeff Bezos-Backed Warehouse Farm Startup Is Building 300 Indoor Farms across China. Available online: http://uk.businessinsider.com/vertical-farming-company-jeff-bezos-plenty-china-2018-1 (accessed on 30 July 2018).

13. REN21 Secretariat. Renewables 2018 Global Status Report; REN21 Secretariat: Paris, France, 2018.

14. Kwon, C.-T.; Heo, J.; Lemmon, Z.H.; Capua, Y.; Hutton, S.F.; van Eck, J.; Park, S.J.; Lippman, Z.B. Rapid customization of Solanaceae fruit crops for urban agriculture. Nat. Biotechnol. 2019, 38, 182-188. [CrossRef] [PubMed]

15. International Energy Agency. Technology Roadmap: Delivering Sustainable Bioenergy; International Energy Agency: Paris, France, 2017.

16. Harris, Z.M.; Spake, R.; Taylor, G. Land use change to bioenergy: A meta-analysis of soil carbon and GHG emissions. Biomass Bioenergy 2015, 82, 27-39. [CrossRef]

17. Mishra, S.K.; Negri, M.C.; Kozak, J.; Cacho, J.F.; Quinn, J.; Secchi, S.; Ssegane, H. Valuation of ecosystem services in alternative bioenergy landscape scenarios. GCB Bioenergy 2019, 11, 748-762. [CrossRef]

18. Index Box. World-Lettuce and Chicory-Market Analysis, Forecast, Size, Trends and Insights; Index Box: California, CA, USA, 2018.

19. AMIS. Global Per Capita Food Use of Wheat from 2000/01 to 2017/18 (in Kilograms Per Year). Available online: https://www.statista.com/statistics/237890/global-wheat-per-capita-food-use-since-2000/ (accessed on 20 October 2018).

20. AMIS. Global Use of Rice Per Capita from 2000/2001 to 2017/2018 (in Kilograms Per Year)*. Available online: https://www.statista.com/statistics/256002/global-per-capita-rice-use-since-2000/ (accessed on 20 October 2018).

21. Cannabis Business Times State of the Cannabis Lighting Market. Available online: https://www. cannabisbusinesstimes.com/article/facility-types/ (accessed on 18 April 2019).

(C) 2020 by the authors. Licensee MDPI, Basel, Switzerland. This article is an open access article distributed under the terms and conditions of the Creative Commons Attribution (CC BY) license (http://creativecommons.org/licenses/by/4.0/). 